\title{
Occurrence of gastrointestinal parasites in camels in the Tianshan Mountains pastoral area in China
}

\author{
Zhang Guowu ${ }^{1 *}$, Zhang Kai ${ }^{1 *}$, Wang Xifeng ${ }^{1 *}$, Ji Chunhui ${ }^{1}$, Ning Chengcheng ${ }^{1}$, \\ Zhao Yue ${ }^{1}$, Qiao Jun ${ }^{1}$, Meng Qingling ${ }^{1 凶}$, Zhang Xingxing ${ }^{2}$, Cai Kuojun ${ }^{3}$, \\ Zhang Jinsheng ${ }^{4}$, Zhang Zaichao ${ }^{5}$, Cai Xuepeng ${ }^{6}$ \\ ${ }^{1}$ College of Animal Science and Technology, Shihezi University, Shihezi, Xinjiang, 832003, China \\ ${ }^{2}$ Institute of Animal Science and Veterinary Research, \\ Xinjiang Academy of Agricultural and Reclamation Science, Shihezi, Xinjiang, 832000, China \\ ${ }^{3}$ Center for Animal Disease Prevention and Control, Urumqi, Xinjiang, 830000, China \\ ${ }^{4}$ Center for Animal Disease Prevention and Control, Tacheng, Xinjiang, 834700, China \\ ${ }^{5}$ Center for Animal Disease Prevention and Control, Changji, Xinjiang, 831500, China \\ ${ }^{6}$ State Key Lab of Veterinary Etiological Biology, Lanzhou Veterinary Research Institute, \\ Chinese Academy of Agricultural Sciences, Lanzhou, Gansu, 730046, China \\ xjmqlqj@sina.com
}

Received: April 21, $2020 \quad$ Accepted: October 12, 2020

\begin{abstract}
Introduction: Gastrointestinal parasites are some of the most common pathogens which are seriously harmful to the camel's health. The infection status of gastrointestinal parasites in camels (Camelus bactrianus) in the Tianshan Mountains pastoral area in China is still unclear. The aim of this study was to investigate the species and infection intensity of gastrointestinal tract parasites in local camels. Material and Methods: A total of 362 fresh faecal samples were collected and examined for parasite eggs using the saturated saline floating and natural sedimentation method. The parasite eggs were subjected to morphological and molecular examination and identification, and the infection rate and mean intensity of the parasites were analysed. Results: A total of 15 gastrointestinal tract parasite species' eggs were identified, with a detection rate of $100 \%$. Ostertagia spp. (100\%) and Trichostrongylus spp. (98.1\%) were dominant. Camels were often coinfected by 5-14 species. The average number of eggs per gram of faeces was higher for Ostertagia spp. (298), Haemonchus contortus (176) and Nematodirus spp. (138). The number of species of parasites infecting young camels was significantly lower than that of adult camels, but the infection intensity in young camels was significantly higher. Conclusion: Gastrointestinal parasites were highly prevalent in camels from the Tianshan Mountains pastoral area in China. This finding provides important epidemiological data for the prevention and control of associated infections in camels.
\end{abstract}

Keywords: Camelus bactrianus, gastrointestinal parasites, Ostertagia spp., Tianshan Mountains pastoral area in China, Trichostronglyus spp.

\section{Introduction}

With a camel population of about 280,000 , China has an abundance of the Camelus bactrianus species and ranks second in the world for head of these ungulates. The Tianshan Mountains pastoral area in Xinjiang, China is a major distribution region of camels, owing to its vast grasslands particularly suitable for extensive animal breeding, and accounts for about $20 \%$ of the total camels in the country. As the "ship of the desert", the camel is an important transportation tool in the Tianshan
Mountains pastoral area, and besides this it also has high nutritional value. Furthermore, camel milk has health protection effects $(2,11,22,25)$, and camel hair can be used as an important textile material. Accordingly, the camel breeding industry has become a cornerstone of the local economy for herders.

Gastrointestinal parasites are one of the most common pathogens, and can not only lead to nutritional and immune inadequacy as well as stunted growth and delayed development (4-8, 23), but also have adverse effects on the quality of camel meat and milk $(18,21)$. 
These consequences of parasitical infection are potential threats to food safety and the health of the majority of herders $(1,9,12,13,27,28)$. In recent years, with the rapid development of the Chinese camel breeding industry in the Tianshan Mountains pastoral area, the number of animals has reached more than 40,000 . Nevertheless, due to the fact that this region's camels are mainly fed by grassland grazing and due to the weak veterinary epidemic prevention and control measures, they are often infected by a variety of gastrointestinal tract parasites, which causes serious financial losses. However, the species and infection intensity of gastrointestinal tract parasites in camels in this region are still unknown.

The purpose of this study is to investigate the species and infection intensity as well as to identify the dominant parasites infecting the gastrointestinal tract of camels in the studied area, which will provide useful epidemiological data for preventing and controlling the parasitic diseases of camels.

\section{Material and Methods}

With a camel population of about 280,000 , China has an abundance of the Camelus bactrianus species and ranks second in the world for head of these ungulates. The Tianshan Mountains pastoral area in Xinjiang, China is a major distribution region of camels, owing to its vast grasslands particularly suitable for extensive animal breeding, and accounts for about $20 \%$ of the total camels in the country. As the "ship of the desert", the camel is an important transportation tool in the Tianshan Mountains pastoral area, and besides this it also has high nutritional value. Furthermore, camel milk has health protection effects $(2,11,22,25)$, and camel hair can be used as an important textile material. Accordingly, the camel breeding industry has become a cornerstone of the local economy for herders.

Gastrointestinal parasites are one of the most common pathogens, and can not only lead to nutritional and immune inadequacy as well as stunted growth and delayed development $(4-8,23)$, but also have adverse effects on the quality of camel meat and milk $(18,21)$. These consequences of parasitical infection are potential threats to food safety and the health of the majority of herders $(1,9,12,13,27,28)$. In recent years, with the rapid development of the Chinese camel breeding industry in the Tianshan Mountains pastoral area, the number of animals has reached more than 40,000. Nevertheless, due to the fact that this region's camels are mainly fed by grassland grazing and due to the weak veterinary epidemic prevention and control measures, they are often infected by a variety of gastrointestinal tract parasites, which causes serious financial losses. However, the species and infection intensity of gastrointestinal tract parasites in camels in this region are still unknown.
The purpose of this study is to investigate the species and infection intensity as well as to identify the dominant parasites infecting the gastrointestinal tract of camels in the studied area, which will provide useful epidemiological data for preventing and controlling the parasitic diseases of camels.

\section{Results}

Overview of the surveyed area's climate and vegetation. The Tianshan Mountains pastoral area in Xinjiang has a temperate continental arid and semi-arid climate. The average annual temperature in northern Xinjiang is $4-9^{\circ} \mathrm{C}$. Its annual precipitation is above $150-200 \mathrm{~mm}$ and its annual frost-free period is $140-185$ days. Considering the southern region, the average annual temperature is $7-14^{\circ} \mathrm{C}$. Its annual precipitation is $25-100 \mathrm{~mm}$, and its annual frost-free period is $180-220$ days. The Tianshan grassland has abundant water sources and a wide variety of pastures; different regions: the high mountain areas are mainly covered with Artemisia and Cyperaceae and partly with miscellaneous grasses, the forest grass lands are mainly covered with leguminous plants and weedy grasses and the low mountainous areas are mainly covered with Bromus pauciflorus, Achnatherum sibiricum, Artemisia, Astragalus, and other grasses.

Collection of camel faeces. During the period of 2016-2018, a total of 362 fresh faecal samples were collected from camels (Camelus bactrianus) in the Tianshan pastoral area of Xinjiang, China. Among them, 106 were from camels younger than two years, 139 were collected from camels aged between two and six years, and 117 were collected from older camels. These fresh faecal samples were collected from the rectum and sealed in $50 \mathrm{~mL}$ plastic bottles, stored at $4^{\circ} \mathrm{C}$, and sent to the Xinjiang Key Laboratory of Animal Disease Prevention and Control. During the collection period, information on clinical manifestations in the camels and deworming records were also collected from local veterinarians or those tending the grazing animals.

Morphological examination and identification of parasite eggs in camel faeces. Eggs were first examined using the saturated saline floating method. In brief, $10 \mathrm{~g}$ of fresh faecal samples were crushed with a glass rod and washed 10 times with saturated saline solution. Then, the mixture was filtered with a 50-mesh copper sieve and collected in a $100 \mathrm{~mL}$ conical beaker. After clarification for $20 \mathrm{~min}$, a wire ring with a diameter of $10 \mathrm{~mm}$ was used to collect the film from the surface of the liquid by parallel contact with the liquid surface and release of the ring's contents onto a glass slide. Simultaneously, parasite eggs in faeces were also collected by the natural sedimentation method. The shape and colour of the parasite eggs were observed and examined under the microscope, and the short and long diameters of the eggs were measured and photographed. The morphological characteristics of each egg were used 
to identify the parasites according to Georgis' Parasitology for Veterinarians (3), Veterinary Clinical Parasitology (26), and Veterinary Parasitology (23).

Molecular detection and identification of parasite eggs in faeces. Nematode eggs with similar morphological structure were identified molecularly. Briefly, the eggs collected from the faeces were processed with a grinder and DNA was extracted using the MiniBEST Universal Genomic DNA Extraction Kit (TaKaRa, Japan). Using the extracted DNA as a template, PCR amplification was performed with specific primers (Table 1) targeting a nematode ribosomal DNA sequence which harbours $18 \mathrm{~S}$ ribosomal RNA, internal transcribed spacer 1 and 5.8S ribosomal RNA. The reaction conditions were as follows: pre-denaturation at $95^{\circ} \mathrm{C}$ for $2 \mathrm{~min}$, denaturation at $94^{\circ} \mathrm{C}$ for $50 \mathrm{~s}$, annealing at $50^{\circ} \mathrm{C}$ for $45 \mathrm{~s}$, and extension at $72^{\circ} \mathrm{C}$ for $30-70 \mathrm{~s}$ in 35 cycles. The PCR products were analysed by electrophoresis on $1.5 \%$ agarose gel. Then they were recovered with the MiniBEST Agarose Gel DNA Extraction Kit (TaKaRa, Japan) and sent to Shanghai Bioengineering Technology Co. Ltd. (Sangon, China) for sequencing. Each sample was sequenced three times. Sequence homology was evaluated in GenBank with Blast $\mathrm{N}$ software, and the species of the eggs were identified according to the homology found.

Determination of parasitic infection intensity in faeces. Infection intensity was determined using Stoll's dilution method. Briefly, a small conical beaker was marked at the capacity of $56 \mathrm{~mL}$ and $60 \mathrm{~mL}$, and $4 \%$ $\mathrm{NaOH}$ solution were added to the $56 \mathrm{~mL}$ mark. Then, about $4 \mathrm{~g}$ of chopped faeces were added slowly until the liquid level reached the $60 \mathrm{~mL}$ mark. Next, more than 10 glass beads were added and the solution was shaken to make a fine and uniform faecal suspension. A $200 \mu \mathrm{L}$ volume of solution was collected on a glass slide, and covered with a rectangle of glass of not less than $22 \mathrm{~mm}$ $\times 40 \mathrm{~mm}$. Finally, the total egg numbers were counted under a microscope. The number multiplied by 100 is the number of eggs per gram of faeces (EPG).

Statistical analysis of data. All data were analysed using SPSS 18 software (IBM SPSS, USA). The continuous variables were compared using an F-test. Data were expressed as mean \pm standard deviation (SD). A P value less than 0.05 was considered significantly different, while a $P$ value less than 0.01 was considered extremely significantly different.

All of the 362 camels were infected with different species of parasite, as detected in their faeces. Based on the morphological (Fig.1) and molecular examinations (Fig. 2), a total of 15 species of parasites eggs were detected and identified in the gastrointestinal tracts of the camels (Table 2), including those of nine species of nematode, three species of trematode, two species of tapeworm, and one species of coccidia.

Among the 15 species of parasite, the particularly highly infective ones were Ostertagia spp. (100\%, 362/362), Trichostrongylus spp. (98.1\%, 355/362), Haemonchus contortus (88.1\%, 319/362), and Nematodirus spp. (87.3\%, 316/362), their prevalences qualifying Ostertagia spp. and Trichostrongylus spp. as dominant species of infecting parasites (Table 2).

All the investigated camels were co-infected with 5-14 different species of parasites (Fig. 3). The number of cases of simultaneous infection with nine species of parasites was the highest, accounting for $23.8 \%$ (86/362), followed in turn by cases of infection with $5,6,7,8,10$, 11,12 , and 13 different species of parasites, accounting for $6.1 \%(22 / 362), 5.0 \%$ (18/362), $9.9 \%$ (36/362), $9.9 \%$

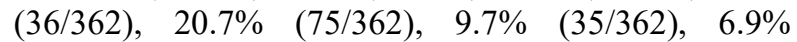
$(25 / 362)$, and $5.8 \%(21 / 362)$, respectively, while the number of 14 -species infections was the lowest, accounting for $2.2 \%$ (8/362) (Fig. 3$)$.

The average number of infectious parasite species in young camels was significantly lower than that in adult ones, but the mean intensity of parasitic infection in this age group shown as EPG of faeces was significantly higher $(\mathrm{P}<0.05)$. The infection intensity in juvenile camels was between that in young and adult animals (Table 3), indicating that parasitic infection has a certain correlation with host age. However, there was no significant difference in the average number of infecting parasite species and infection intensity between male and female camels $(\mathrm{P}>0.05)$, indicating no correlation between parasitic infection and gender.

Table 1. Primers used in the study

\begin{tabular}{lccc}
\hline Primer & Nucleotide sequence $\left(5^{\prime}\right.$ to $\left.3^{\prime}\right)$ & Target gene & $\begin{array}{c}\text { Size of amplified product } \\
\text { (bp) }\end{array}$ \\
\hline FP1 & AGGTATCTGTAGGTGAACCTGC & Ribosomal ITS1 of Haemonchus contortus & 810 \\
RP1 & ATACAAATGATAAAAGAACATC & & \\
FP2 & GAGAGGACTGCGGACTGCTGTA & Ribosomal ITS1 of Trichostrongylus spp. & 240 \\
RP2 & CTCACACACAGAGCTCTAACGG & & 475 \\
FR3 & CTGCGGAAGGATCATTGTCGAA & Ribosomal ITS1 of Chabertia ovina & \\
RP3 & ACTCTAAGCGTCTGCAATTCGT & & 475 \\
FR4 & TGTACACACCGCCCGTCGCTGT & Ribosomal ITS1 of Ostertagia spp. \\
RP4 & TGACAACCAGGTACCGTACACA & & 475 \\
FR5 & GGACTGCGGACTGCTGTATCGA & Ribosomal ITS1 of Bunostomum spp. \\
RP5 & TGTTAAACGTAAAAAATTGTT & & \\
\hline
\end{tabular}




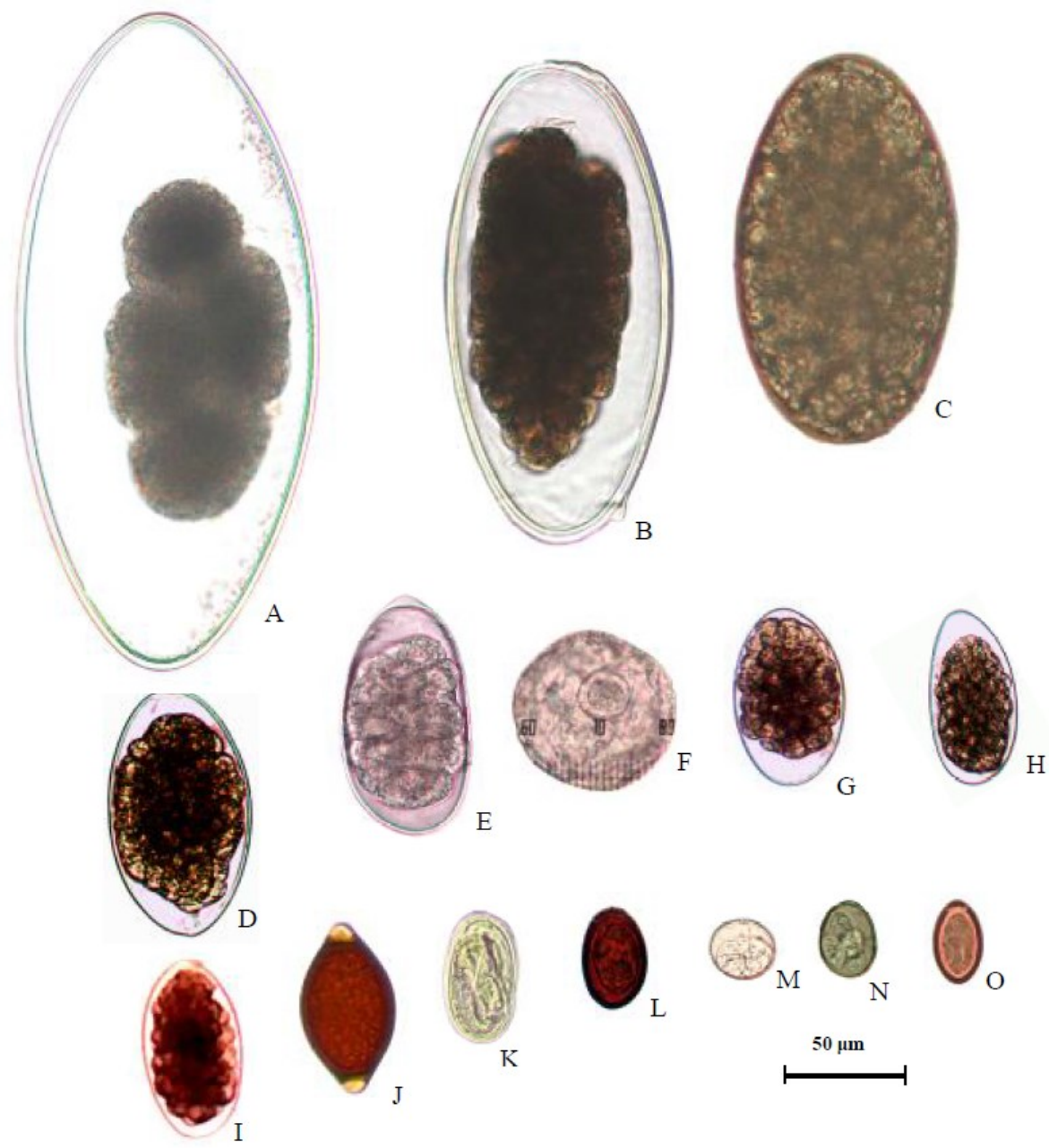

Fig. 1. Morphological characteristics of eggs of different parasitic worms in the faeces of camels in the Tianshan Mountains pastoral area

A - Nematodirus spp.; B - Marshallagia spp.; C - Fasciola hepatica; D - Chabertia ovina; E - Bunostomum spp.; F-Moniezia expansa; G - Haemonchus contortus; $\mathrm{H}$ - Trichostrongylus spp.; I - Ostertagia spp.; J - Trichuris spp.; $\mathrm{K}$ - Strongyloides papillosus; $\mathrm{L}$ - Dicrocoelium spp.; M - Eimeria spp.; $\mathrm{N}$ - Thysaniezia ovilla; $\mathrm{O}$ - Hasstilesia ovis

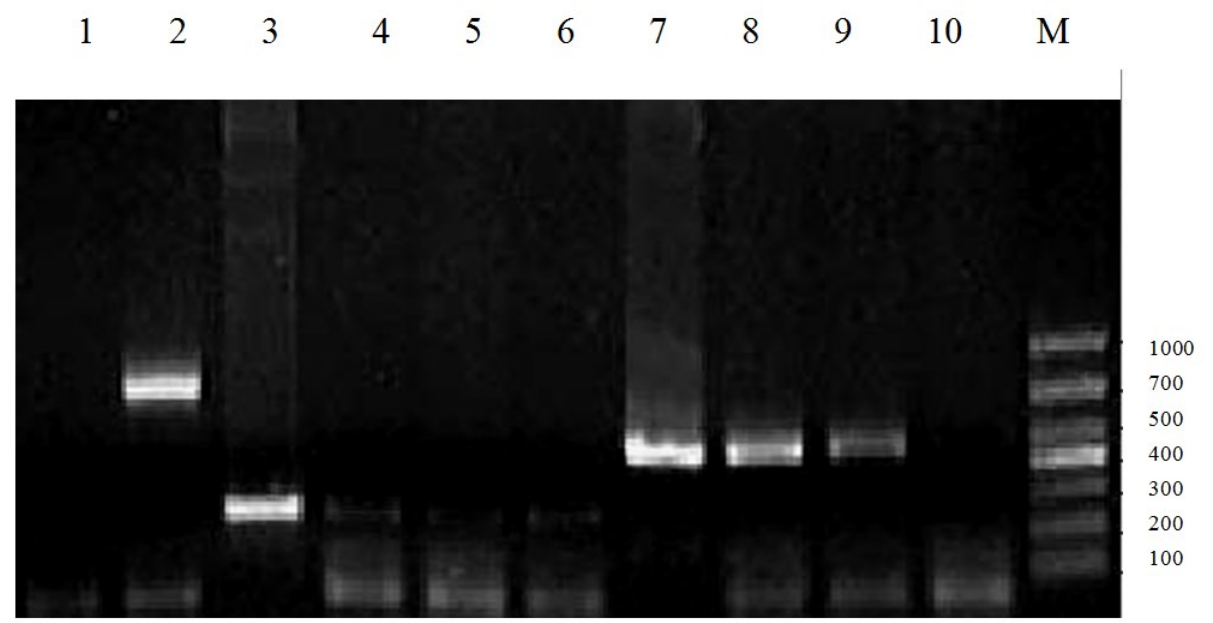

Fig. 2. Molecular detection of nematode eggs with similar morphological structure in camel faeces

M - DNA maker DL1000 (1000, 700, 500, 400, 300, 200, 100 bp); Lanes 1, 4, 5, 6, and 10 - negative results; Lane 2 - Haemonchus contortus; Lane 3 - Trichostrongylus spp.; Lane 7 - Chabertia ovina; Lane 8 - Ostertagia spp.; Lane 9 - Bunostomum spp. 
Table 2. Summary statistics of gastrointestinal parasites in camels in the Tianshan Mountains pastoral area

\begin{tabular}{|c|c|c|c|c|}
\hline Parasite species & $\begin{array}{c}\text { Infection rate } \\
(\%)\end{array}$ & Mean EPG & $\begin{array}{l}\text { Length of egg } \\
(\mu \mathrm{m})\end{array}$ & $\begin{array}{l}\text { Width of egg } \\
(\mu \mathrm{m})\end{array}$ \\
\hline Ostertagia spp. & $100(362 / 362)$ & $298 \pm 57.1$ & $71.25 \pm 9.12$ & $36.44 \pm 4.57$ \\
\hline Trichostrongylus spp. & $98.1(355 / 362)$ & $105 \pm 36.2$ & $82.24 \pm 10.83$ & $39.63 \pm 3.53$ \\
\hline Haemonchus contortus & $88.1(319 / 362)$ & $176 \pm 62.5$ & $75.65 \pm 5.78$ & $46.35 \pm 7.88$ \\
\hline Nematodirus spp. & $87.3(316 / 362)$ & $138 \pm 41.8$ & $241.36 \pm 23.14$ & $111.93 \pm 18.51$ \\
\hline Marshallagia spp. & $80.4(291 / 362)$ & $129 \pm 38.7$ & $182.89 \pm 11.90$ & $81.56 \pm 7.42$ \\
\hline Trichuris spp. & $77.3(281 / 362)$ & $93 \pm 22.9$ & $75.42 \pm 6.57$ & $35.27 \pm 3.46$ \\
\hline Chabertia ovina & $18.2(66 / 362)$ & $71 \pm 10.4$ & $89.24 \pm 8.33$ & $52.26 \pm 5.72$ \\
\hline Bunostomum spp. & $9.9(36 / 362)$ & $45 \pm 14.8$ & $88.67 \pm 7.91$ & $48.22 \pm 2.35$ \\
\hline Strongyloides papillosus & $33.1(120 / 362)$ & $113 \pm 8.7$ & $51.78 \pm 8.75$ & $30.58 \pm 5.67$ \\
\hline Thysaniezia ovilla & $60.8(220 / 362)$ & $126 \pm 29.4$ & $25.18 \pm 3.15$ & $22.34 \pm 2.78$ \\
\hline Moniezia expansa & $42.3(153 / 362)$ & $103 \pm 41.1$ & $63.13 \pm 4.32$ & $46.86 \pm 5.31$ \\
\hline Dicrocoelium spp. & $62.4(226 / 362)$ & $82 \pm 6.8$ & $39.19 \pm 4.74$ & $31.25 \pm 3.16$ \\
\hline Fasciola hepatica & $24.6(89 / 362)$ & $20 \pm 13.5$ & $140.55 \pm 7.68$ & $84.54 \pm 8.12$ \\
\hline Hasstilesia ovis & $91.7(332 / 362)$ & $56 \pm 17.5$ & $30.12 \pm 3.81$ & $18.32 \pm 1.72$ \\
\hline Eimeria spp. & $73.5(266 / 362)$ & $94 \pm 16.2$ & $34.18 \pm 2.32$ & $22.17 \pm 1.72$ \\
\hline
\end{tabular}

Table 3. Prevalence of gastrointestinal parasites in camels in the Tianshan Mountains pastoral area

\begin{tabular}{cllcr}
\hline & Potential propensity factor & $\begin{array}{c}\text { Number of } \\
\text { examined camels }\end{array}$ & $\begin{array}{c}\text { Mean number of } \\
\text { parasite species in } \\
\text { co-infection }\end{array}$ & Mean EPG \\
\hline \multirow{3}{*}{ Age } & Young camels (>2 years) & 106 & $6 \pm 1.6^{\mathrm{a}}$ & $1046 \pm 87.2^{\mathrm{a}}$ \\
& Sub-adult camels (2-6 years) & 139 & $7 \pm 1.8^{\mathrm{a}}$ & $779 \pm 39.6^{\mathrm{a}}$ \\
& Adult camels (>6 years) & 117 & $11 \pm 1.5^{\mathrm{b}}$ & $462 \pm 40.7^{\mathrm{b}}$ \\
& Male & 206 & $9 \pm 1.2^{\mathrm{a}}$ & $901 \pm 85.5^{\mathrm{a}}$ \\
\hline
\end{tabular}

Different letters in same column mean significant difference $(\mathrm{P}<0.05)$

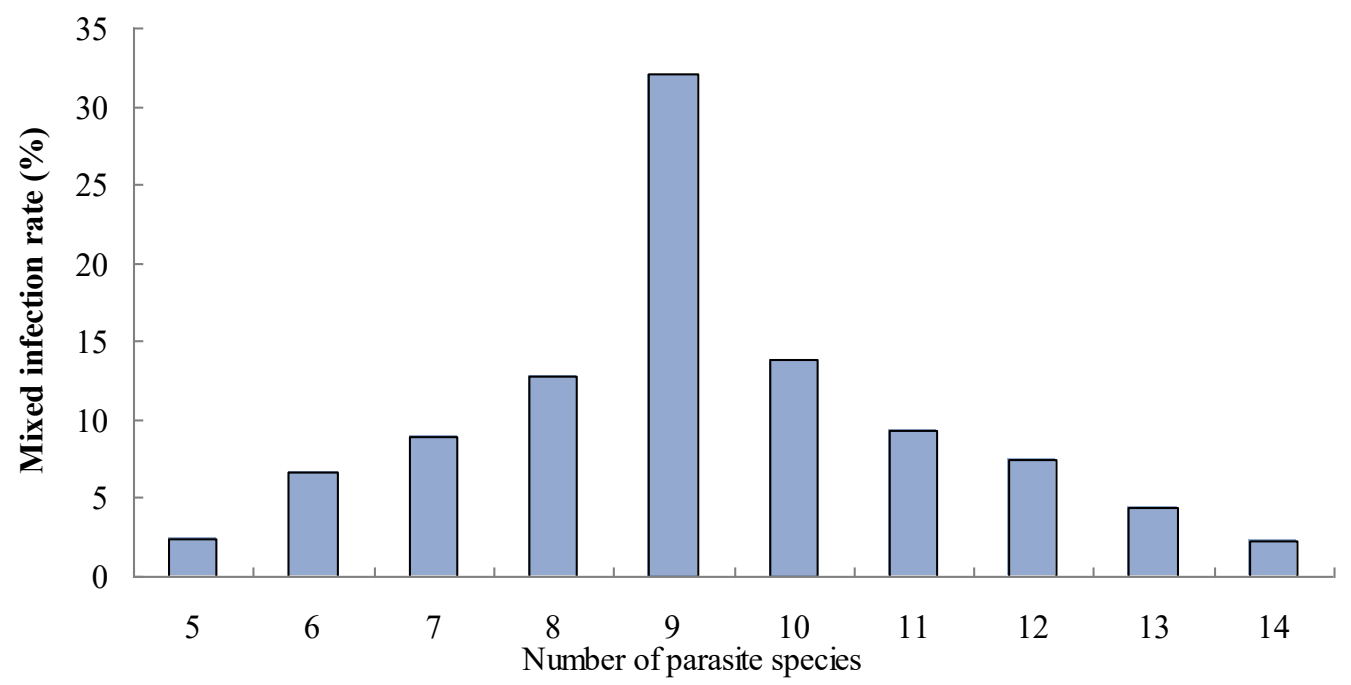

Fig. 3. Mixed infection with different species of gastrointestinal parasite in camels in the Tianshan Mountains pastoral area

\section{Discussion}

Parasitic disease is a disease that seriously endangers the development of the camel industry $(18,20$, $22,24)$ and that not only impedes the growth and development of camels $(14,17,19)$, but is also one of the important reasons for the peak in camel deaths in the spring, resulting in great economic losses $(15,16,21)$. What is more, many zoonotic parasites $(1,9,10,12,13$, 28 ) could contaminate camel milk (18) and meat, posing potential threats to food safety and the health of the majority of herders $(9,21,22)$. The documents on camel parasitic diseases in Iran showed that 48 helminth species were detected in the digestive system (21). Therefore, the investigation of the prevalence of gastrointestinal parasites in camels in the Tianshan pastoral area is of great significance for improving the economic output of the camel industry and preventing the spread of parasitic zoonosis.

Many studies reported that the helminth is particularly rich in the digestive tract of camelids, which is more than 40 species $(17,21)$. Among them, 
Trichostrongylus spp. and Haemonchus contortus are the most common species (21). In our study, we systematically investigated the infection status of camel gastrointestinal parasites in the Tianshan Mountains pastoral area. A total of 15 species of camel gastrointestinal parasite were identified, including 9 species of nematodes, 3 species of tapeworm, 2 species of trematode, and 1 species of coccidian. All camels suffered from mixed infections of 5-14 parasite species. Among them, Ostertagia spp. and Trichostrongylus spp. were the dominant species. The average number of infected parasites in young camels was significantly lower than in adult camels, but the young camel EPG was significantly higher than that of adult camels, which may be related to the weak immune system and incomplete establishment of parasite immunity in juvenile camels. Our epidemiological surveys also suggested that irregular deworming and being grazed and housed together with cattle and sheep were partially responsible for high prevalence of parasites in camels.

In addition, this survey also showed that mixed parasitic infections were very common in camels, which was consistent with the clinical manifestations (diarrhoea, hair loss, reproductive rate decline, and high mortality) of the camel population under investigation. We found that the pathogenicity of a parasite was related to the level of infection, while characteristics of individual species seemed to play a lesser role in pathogenicity. This survey also found a large number of eggs of nematodes in the Ostertagia, Trichostrongylidae, Haemonchus, and Bunostomum genera. These eggs were difficult to distinguish and identify at the level of species, and so they were further subjected to molecular identification.

To our knowledge, this was the first systematic survey on the prevalence of gastrointestinal parasites in C. bactrianus in the Tianshan Mountains pastoral area in China, and it offers useful epidemiological data for the prevention and control of gastrointestinal parasite infection in camels. In conclusion, gastrointestinal parasite infection in camels was very common in the Tianshan pasture. Therefore, it is necessary to take effective measures such as deworming and rotational grazing to prevent and control the parasite infection in camels.

Conflict of Interests: The authors declare that there is no conflict of interests regarding the publication of this article.

Financial Disclosure Statement: This work was supported by the National Key Research and Development Program (No. 2017YFD0501200), the National International Science and Technology Cooperation Exchange Project (No. CK 07-11), the Xinjiang Autonomous Region Graduate Innovation project (No. XJ2017G085) and the International Science and Technology Cooperation Program Project of XPCC (No. 2016AH006).
Animal Rights Statement: The authors declare that the experiments on animals were approved by the Research and Ethical Committee of Shihezi University (RECSHZ2020166).

Acknowledgments: We thank the field staff who provided the samples for this study.

*These authors contributed equally to the article and should be considered co-first authors.

\section{References}

1. Alam-Eldin Y.H., Abdel Aaty H.E., Ahmed M.A.: Molecular characterization of cystic echinococcosis: First record of G7 in Egypt and G1 in Yemen. Acta Parasitol 2015, 60, 662-665.

2. Badawy A.A., El-Magd M.A., AlSadrah S.A.: Therapeutic effect of camel milk and its exosomes on MCF7 cells in vitro and in vivo. Integr Cancer Ther 2018, 17, 1235-1246.

3. Bowman D.D.: Georgis' Parasitology for Veterinarians, Saunders, St. Louis, 2009

4. Cafrune M.M., Aguirre D.H., Rickard L.G.: Recovery of Trichuris tenuis Chandler, 1930, from camelids (Lama glama and Vicugna vicugna) in Argentina. J Parasitol 1999, 85, 961-962.

5. Dubey J.P., Hilali M., Van Wilpe E., Calero-Bernal R., Verma S.K., Abbas I.E.: A review of sarcocystosis in camels and redescription of Sarcocystis cameli and Sarcocystis ippeni sarcocysts from the one-humped camel (Camelus dromedarius). Parasitol 2015, 142, 1481-1492.

6. Dubey J.P., Schuster R.K.: A review of coccidiosis in Old World camels. Vet Parasitol 2018, 262, 75-83.

7. Dubey J.P., Schuster R.K., Kinne J.: Gametogony of Eimeria cameli in the small intestine of one-humped camel (Camelus dromedarius). Parasitol Res 2018, 117, 3633-3638.

8. Ederli N.B., de Oliveira F.C.: Gastrointestinal nematodes in ostriches, Struthio camelus, in different regions of the state of Rio de Janeiro, Brazil. Rev Bra Parasitol Vet 2015, 24, 168-173.

9. Fatima T., Mehnaz S., Wang M., Yang J., Sajid M.S., Shen B., Zhao J.: Seroprevalence of Toxoplasma gondii in one-humped camels (Camelus dromedarius) of Thal and Cholistan deserts, Punjab, Pakistan. Parasitol Res 2019, 118, 307-316.

10. Feng Y., Lu Y., Wang Y., Zhang L., Yang Y.: Toxoplasma gondii and Neospora caninum in farm-reared ostriches (Struthio camelus) in China. BMC Vet Res 2017, 13, 301.

11. Ibrahim H.R., Isono H., Miyata T.: Potential antioxidant bioactive peptides from camel milk proteins. Anim Nutr 2018, 4, 273-280.

12. Jarvinen J.A., Dubey J.P., Althouse G.C.: Clinical and serologic evaluation of two llamas (Lama glama) infected with Toxoplasma gondii during gestation. J Parasitol 1999, 85, 142-144.

13. Li Y., Yang J., Chen Z., Qin G., Li Y., Li Q., Liu J., Liu Z., Guan G., Yin H., Luo J., Zhang L.: Anaplasma infection of Bactrian camels (Camelus bactrianus) and ticks in Xinjiang, China. Parasit Vectors 2015, 8, 313.

14. Metwally D.M., Qassim L.E., Al-Turaiki I.M., Almeer R.S., El-Khadragy M.F.: Gene-based molecular analysis of COX1 in Echinococcus granulosus cysts isolated from naturally infected livestock in Riyadh, Saudi Arabia. PLoS One 2018, 13, e0195016.

15. Mirshekar F., Yakhchali M., Shariati-Sharifi F.: Trypanosoma evansi infection and major risk factors for Iranian one-humped camels (Camelus dromedarius). J Parasitic Dis 2017, 41, 854-858.

16. Mirzaei M., Ghahvei Y., Lefoulon E., Lia R.P., Otranto D., Martin C., Sazmand A.: Morphological and molecular characterization of Onchocerca fasciata (Nematoda, Onchocercidae) from dromedary camels (Camelus dromedarius) in Iran. Parasite 2018, 25, 50. 
17. Pathak K.M., Chhabra M.B.: Parasites and parasitic diseases of the camel in India: a review. Indian J Anim Sci 2010, 80, 699-706.

18. Saad N.M., Hussein A.A.A., Ewida R.M.: Occurrence of Toxoplasma gondii in raw goat, sheep, and camel milk in Upper Egypt. Vet World 2018, 11, 1262-1265.

19. Saeed M.A., Vaughan J.L., Jabbar A.: An update on sarcocystosis in one-humped camels (Camelus dromedarius). Parasitol 2018, $145,1367-1377$.

20. Sazmand A., Eigner B., Mirzaei M., Hekmatimoghaddam S.H., Harl J., Duscher G.G., Fuehrer H.P., Joachim A.: Molecular identification of hemoprotozoan parasites in camels (Camelus dromedarius) of Iran. Iran J Parasitol 2016, 11, 568-573.

21. Sazmand A., Joachim A.: Parasitic diseases of camels in Iran (1931-2017) - a literature review. Parasite 2017, 24, 21.

22. Sazmand A., Joachim A., Otranto D.: Zoonotic parasites of dromedary camels: so important, so ignored. Parasit Vectors 2019, 12,610 .
23. Taylor M.A., Coop R.L., Wall R.L.: Veterinary Parasitology, Blackwell, Oxford, 2007.

24. Ukashatu S., Saulawa M.A., Magaji A.A.: Epidemiology of gastrointestinal parasites of one-humped camel (Camelus dromedarius) slaughtered in Sokoto central abattoir, Sokoto state, Nigeria. Sci J Vet Adv 2013, 1, 723-832.

25. Wang Z., Zhang W., Wang B., Zhang F., Shao Y.: Influence of Bactrian camel milk on the gut microbiota. J Dairy Sci 2018, 101, 5758-5769.

26. Zajac A.M., Conboy G.A.: Veterinary Clinical Parasitology, Wiley Blackwell, Ames, 2006.

27. Zhai B., Niu Q., Liu Z., Yang J., Pan Y., Li Y., Zhao H., Luo J., Yin H.: First detection and molecular identification of Borrelia species in Bactrian camel (Camelus bactrianus) from Northwest China. Infect Genet Evol 2018, 64, 149-155.

28. Zhu S., Zimmerman D., Deem S.L.: A review of zoonotic pathogens of dromedary camels. Ecohealth 2019, 16, 356-377. 